EXTENDED REPORT

\title{
Evaluation of the symptomatic and structural efficacy of a new hyaluronic acid compound, NRD101, in comparison with diacerein and placebo in a 1 year randomised controlled study in symptomatic knee osteoarthritis
}

\author{
T Pham, A Le Henanff, Ph Ravaud, P Dieppe, L Paolozzi, M Dougados
}

Ann Rheum Dis 2004;63:1611-1617. doi: 10.1136/ard.2003.019703

See end of article for authors' affiliations

Correspondence to: Professor M Dougados, Rheumatology B Department, Cochin Hospital, 27 rue du Faubourg Saint Jacques, 75014 Paris, France; maxime.dougados@cch. ap-hop-paris.fr

Accepted 27 April 2004 Published Online First 26 August 2004

Objective: To evaluate long term efficacy of three iterative courses of three weekly intra-articular (IA) injections of NRD101 in the treatment of symptomatic knee osteoarthritis (OA).

Patients and methods: A 1 year prospective, multicentre, randomised, double blind, placebo controlled study of 301 patients aged $>50$ years with painful and radiological medial knee OA. Patients were randomly assigned into three groups receiving: (1) three courses of three IA injections of hyaluronic acid (HA) + oral placebo; (2) IA injections of saline solution + diacerein $100 \mathrm{mg} /$ day; (3) IA injections of saline solution + oral placebo. Demographic data and symptomatic criteria-pain, Lequesne's index, patient's global assessment of disease activity, percentage of painful days-were obtained during the study; primary structural criterion was JSW. Efficacy criteria were changes in pain VAS, joint space narrowing (JSN), and percentage of progressors (JSN $>0.5 \mathrm{~mm}$ ). An intention to treat analysis was used for symptomatic variables, and completer analysis for structural variables.

Results: Baseline characteristics were similar between the three groups. Mean (SD) improvement in pain VAS was clinically relevant $(-33.9(27.3), n=301)$, but with no difference between the groups $(p=0.96)$. JSW deteriorated $(-0.09(0.55) \mathrm{mm}, \mathrm{n}=277, \mathrm{p}=0.01)$, but with no difference between the groups $(p=0.82)$. Percentages of progressors were $17.7,18.9$, and $20.3 \%(p=0.90)$, in groups 1 , 2 , and 3 , respectively.

Conclusion: A weak but statistically significant structural deterioration occurred over 1 year, together with clinically relevant symptomatic improvement in patients receiving oral drug and iterative IA injections. Symptomatic and/or structural effects for both this new HA compound and diacerein were not demonstrated.

O steoarthritis (OA) is a major cause of disability and is among the most prevalent form of musculoskeletal diseases. ${ }^{12}$ Drugs for the treatment of OA have been classified as symptom modifying and structure modifying drugs. Until now, no drug can be included in the latter category. However, several compounds could be considered as potentially delaying the disease progression. ${ }^{3-5}$ These potentially structure modifying drugs can be classified according to their administration route: by mouthfor example, diacerein or glucosamine sulphate, or intraarticular (IA)-for example, hyaluronic acid (HA).

Diacerein, a purified compound with an anthraquinone structure, has been shown to inhibit, in vitro and in vivo, the production and activity of interleukin 1 and the secretion of metalloproteinases, without affecting the synthesis of prostaglandins. ${ }^{6-9}$ There is evidence that diacerein has both a significant symptomatic (pain) and a structural effect compared with placebo, at least in hip OA. ${ }^{10} 11$

HA is a high molecular weight polysaccharide, which is a major component of synovial fluid and cartilage. In OA, the molecular weight and concentration of HA are diminished. The concept of viscosupplementation suggests that IA injection of HA might help to restore the viscoelasticity of the synovial fluid. ${ }^{12}$ HA has been used as a pain reliever for patients with OA, particularly in the knee joint. ${ }^{12-14}$ Furthermore, data have suggested that HA may have a beneficial structural effect in OA. ${ }^{45}$ However, the efficacy of this treatment remains the subject of debate. ${ }^{16-18}$

NRD101 is a new HA compound produced from Streptococcus equus by fermentation on vegetable or synthetic based mediums not containing human or animal based products. Its average molecular weight is $1.900 \mathrm{kDa}$ (concentration $1 \%, 25 \mathrm{mg}$ of sodium hyaluronate in $2.5 \mathrm{ml}$; Hoechst Marion Roussel). In phase II and III studies in Japan, various treatment schedules were studied using five or more infiltrations at various concentrations and volumes, from which they determined that NRDI01 was safe and that the optimal dosage was $2.5 \mathrm{ml}$ weekly (unpublished data). A preliminary open study compared the efficacy of five weekly courses of IA injections of NDR101 and another HA compound, Artz (0.600-1.200 kDa) in 182 patients with knee OA. Patients had to evaluate the treatment efficacy at the end of the study using a seven level Likert scale. In the NRD101 group $(n=95), 72.6 \%$ of the patients considered their treatment at least moderately effective compared with $58.6 \%$ in the Artz group $(\mathrm{n}=87), \mathrm{p}<0.05 .{ }^{19} 20$

The main purpose of our study was to evaluate the long term symptomatic and structural efficacy and safety of three

Abbreviations: $H A$, hyaluronic acid; IA, intra-articular; JSN, joint space narrowing; JSW, joint space width; NSAIDs, non-steroidal antiinflammatory drugs; OA, osteoarthritis; VAS, visual analogue scale 
IA injection sequences of NRDI0l over 1 year in the treatment of symptomatic knee OA, compared with diacerein and with placebo. As far as we know, this study is the first comparing a potential oral structure modifying drug with an IA anti-osteoarthritic drug in knee OA.

\section{PATIENTS AND METHODS}

\section{Patients}

Outpatients fulfilling the American College of Rheumatology clinical or radiological criteria for the diagnosis of knee OA were recruited for the study through 46 rheumatology departments in France.

The main inclusion criterion was the presence of a symptomatic primary painful medial femorotibial knee OA defined by a daily pain visual analogue scale (VAS) score $>30 \mathrm{~mm}$ in the previous month. If both knees were symptomatic, only the most painful one was taken into account. The radiographic inclusion criterion was medial joint space width (JSW) $>2 \mathrm{~mm}$. The radiographic evidence of knee OA, eligibility criteria, and the quality of the radiographic films were verified by a central reader $(\mathrm{PhR})$ before inclusion of a patient in the study.

The main exclusion criteria were evidence of secondary knee OA (possibly due to injury, inflammatory or metabolic rheumatic disease, osteonecrosis, Paget's disease, villonodular synovitis, haemophilia); prior intra-articular HA treatment; other IA injection, including lavage and corticosteroids within the previous 3 months; treatment with diacerein in the 3 months before inclusion and use of any other antiosteoarthritic drugs in the 2 months before inclusion; contraindication to IA injection (anticoagulants, haematological anomalies); and severe knee OA (JSW $<2 \mathrm{~mm}$, surgery required on the evaluated knee in the year).

\section{Study design}

This prospective, multicentre, randomised, double blind, 12 month, placebo controlled study was conducted in accordance with the 1964 Declaration of Helsinki and its subsequent endorsements, and was approved by the review board of the Cochin Hospital, Paris, France. Patients entered the study after reading and signing an informed consent form.

\section{Drug administration}

The patients were randomly assigned to receive one undistinguishable capsule of either placebo or diacerein at a dose of $50 \mathrm{mg}$ twice daily as well as three courses, every three months, of three weekly IA injections of either saline solution or HA (NRD101).

The randomised allocation schedule was centralised (Cassenne Laboratories, Osny, France). According to a preestablished randomisation code, the treatment sequence was: (a) $3 \times 3$ HA IA injections (NRDI01) and daily placebo capsules; or $(b) 3 \times 3$ IA injections of saline solution and daily diacerein capsules; or (c) $3 \times 3$ IA injections of saline solution and daily placebo capsules. The saline vehicle was expected to have only a placebo effect and was considered as an IA control. Whatever the treatment group, the IA injection procedure was the following: subcutaneous lidocaine local anaesthesia, aspiration of synovial fluid (if present), and injection of the $2.5 \mathrm{ml}$ contained in the pre-filled syringes. The practitioner who carried out the injections did not evaluate the patient to avoid evaluation bias.

All treatments were recorded in the case report form at each clinic visit throughout the study. Patients were allowed to take analgesics as rescue drug. However, before each evaluation visit, they were required to undergo a 2 day

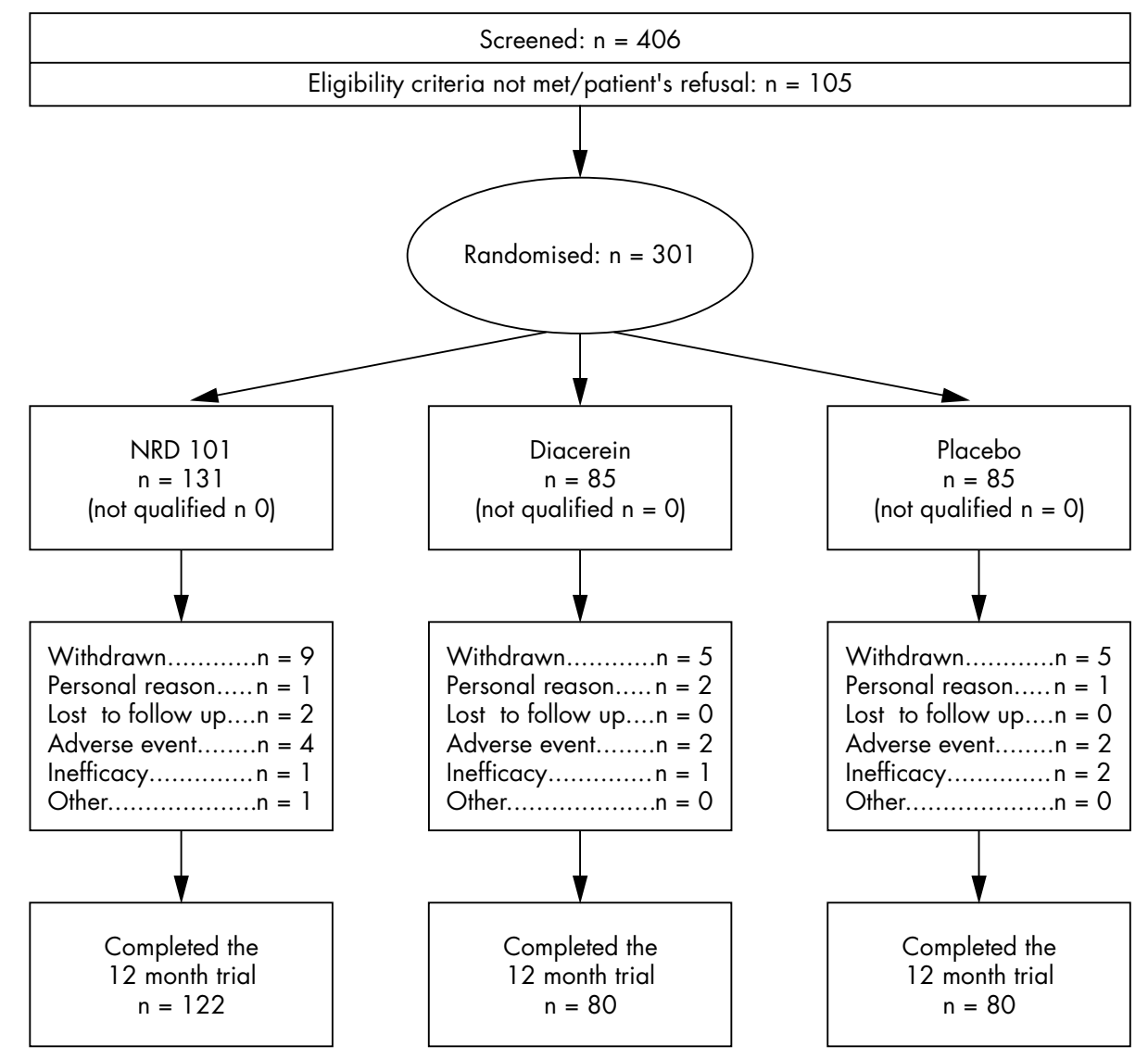

Figure 1 Course of the 20 month randomised trial. 
Table 1 Baseline characteristics of the 301 randomised and treated patients with medial knee OA with regards to the treatment group

\begin{tabular}{|c|c|c|c|}
\hline Baseline characteristics & $\begin{array}{l}\text { NRD101 } \\
(n=131)\end{array}$ & $\begin{array}{l}\text { Diacerein } \\
(\mathrm{n}=85)\end{array}$ & $\begin{array}{l}\text { Placebo } \\
(n=85)\end{array}$ \\
\hline \multicolumn{4}{|l|}{ Demographic characteristics } \\
\hline Age (years) & $64.9(8.4)$ & $64.5(7.8)$ & $64.9(7.7)$ \\
\hline Sex (\% female) & 71.0 & 69.4 & 61.2 \\
\hline Weight $(\mathrm{kg})$ & $76.8(14.0)$ & $78.0(13.9)$ & $79.7(14.5)$ \\
\hline Height $(\mathrm{cm})$ & $164.1(9.3)$ & $162.9(7.9)$ & $163.5(8.9)$ \\
\hline Right knee, No (\%) & $65(50)$ & $41(48)$ & $48(56)$ \\
\hline \multicolumn{4}{|l|}{ Symptomatic variables } \\
\hline Pain score on $0-100$ VAS & $61.7(13.6)$ & $59.6(12.5)$ & $59.1(14.7)$ \\
\hline Functional impairment (Lequesne's index) & $11.1(2.8)$ & $10.5(2.6)$ & $10.5(3.1)$ \\
\hline Patient's global assessment (0-100 VAS ) & $59.7(15.9)$ & $59.0(17.0)$ & $57.3(18.5)$ \\
\hline $\begin{array}{l}\text { Percentage of painful days during the previous month } \\
\text { (0-100 VAS) }\end{array}$ & $85.5(20.4)$ & $83.0(18.5)$ & $82.6(21.0)$ \\
\hline Structural variables & ( $n=127$ ) & $(n=82)$ & (n = 83) \\
\hline Joint space width $(\mathrm{mm})$ & $4.5(1.2)$ & $4.5(1.1)$ & $4.7(1.3)$ \\
\hline Osteophyte score (4 grades), No (\%) & ( $n=128)$ & $(\mathrm{n}=84)$ & $(n=83)$ \\
\hline 0 & $5(4)$ & $4(5)$ & $5(6)$ \\
\hline 1 & $53(41)$ & 41 (49) & $36(43)$ \\
\hline 2 & $59(46)$ & 31 (37) & $40(48)$ \\
\hline 3 & $11(9)$ & $8(10)$ & $2(2)$ \\
\hline Kellgren and Lawrence score (5 grades), No (\%) & $(n=129)$ & $(\mathrm{n}=84)$ & $(n=83)$ \\
\hline 0 & $1(0.8)$ & $0(0)$ & $0(0.00)$ \\
\hline 1 & $4(3)$ & $3(4)$ & $2(2)$ \\
\hline 2 & $30(23)$ & $12(14)$ & $19(23)$ \\
\hline 3 & $90(70)$ & 66 (79) & $60(72)$ \\
\hline 4 & $4(3)$ & $3(4)$ & $2(2)$ \\
\hline
\end{tabular}

washout period. Aspirin at an antiplatelet dose $(<500 \mathrm{mg} /$ day) was allowed. If non-steroidal anti-inflammatory drugs (NSAIDs) were required, the drugs used were those with an equivalent dosage available, and a 7 day washout period was required before each evaluation visit. No systemic corticosteroid, IA treatment (lavage, HA, corticosteroid), or any potential symptom modifying drug was allowed during the study.

\section{Collected variables}

Baseline evaluation

Age, sex, weight, height, past history of knee OA, and treatment were noted.

\section{Symptomatic efficacy criteria}

Pain on a 0-100 VAS, Lequesne's algofunctional index, patient's global assessment of disease activity (0-100 VAS), and percentage of painful days during the previous months (0-100 VAS) were collected at baseline, weeks 1, 2, 6, and months 4, 6, 8 10, 12. Global assessments of the treatment efficacy by the patient and by the investigator (five level Likert scale) were noted at the end of the study. The use of concomitant treatments (analgesics, NSAIDs) was evaluated by the numbers of days of intake between each clinic visit.

\section{Structural efficacy criteria}

The structure of the OA knee was evaluated by radiography at baseline and at the final visit or at the end of the follow up. The $x$ ray procedure was strictly standardised. Anteroposterior radiographs of the knee joints were obtained with patients in a weightbearing position, joint fully extended, standing at $1 \mathrm{~m}$ from the $x$ ray source, with a constant and reproducible foot position using previously published guidelines ${ }^{21}{ }^{22}:(a)$ the distance between the back of the knees and the plate was noted; $(b)$ the feet were rotated $10^{\circ}$ internally and the position of the feet outlined on a sheet of paper (foot map); (c) the central ray of the $x$ ray beam was centred on the joint space and inclined downward to ensure that the medial tibial plateau was parallel to the $x$ ray beam. The angle of inclination was noted and reproduced on the final visit for radiography.

All films were centralised and duplicated for each observer (PD, PhR). At the end of the study the films of the same patient were analysed by the two observers who were unaware of the treatment, the sequence of radiographs, and the results of the other observer. The observer determined the location of the narrowest point of the JSW on the radiograph of a given knee (minimal JSW), then transferred this point to the other films of the set being measured, judging by eye. The anatomical limits for measurement of the JSW were the bone contour of the medial tibial plateau (the anterior side if the anterior and the posterior sides were not correctly aligned) and the bone contour of the medial femoral condyle. Both limits were marked with a short stroke of a dedicated pencil. The distance between these limits was measured with a $0.1 \mathrm{~mm}$ graduated magnifying glass. Each observer separately determined the narrowest point. The mean of the results of the two observers was the JSW measure used.

The intra- and interobserver reproducibilities were evaluated for the study and were considered to be acceptable: interobserver intraclass correlation coefficient 0.912 (0.887$0.931)$ and intraobserver (PD, PhR) intraclass correlation coefficient 0.996 (0.991-0.998) and 0.992 (0.989-0.996), respectively.

The observers also assessed the Kellgren and Lawrence grade of the femorotibial joints. ${ }^{23}$ Osteophytes were assessed using the Altman atlas. ${ }^{24}$

\section{Evaluation of safety}

During each visit, the investigators evaluated the safety measures. In addition, at the time of entry into the study and at the final visit, blood samples were collected to evaluate biological variables as well as liver and kidney functions. Global assessment of treatment safety by the investigator (five level Likert scale) was also recorded at baseline, months 4,8 , and 12 . 


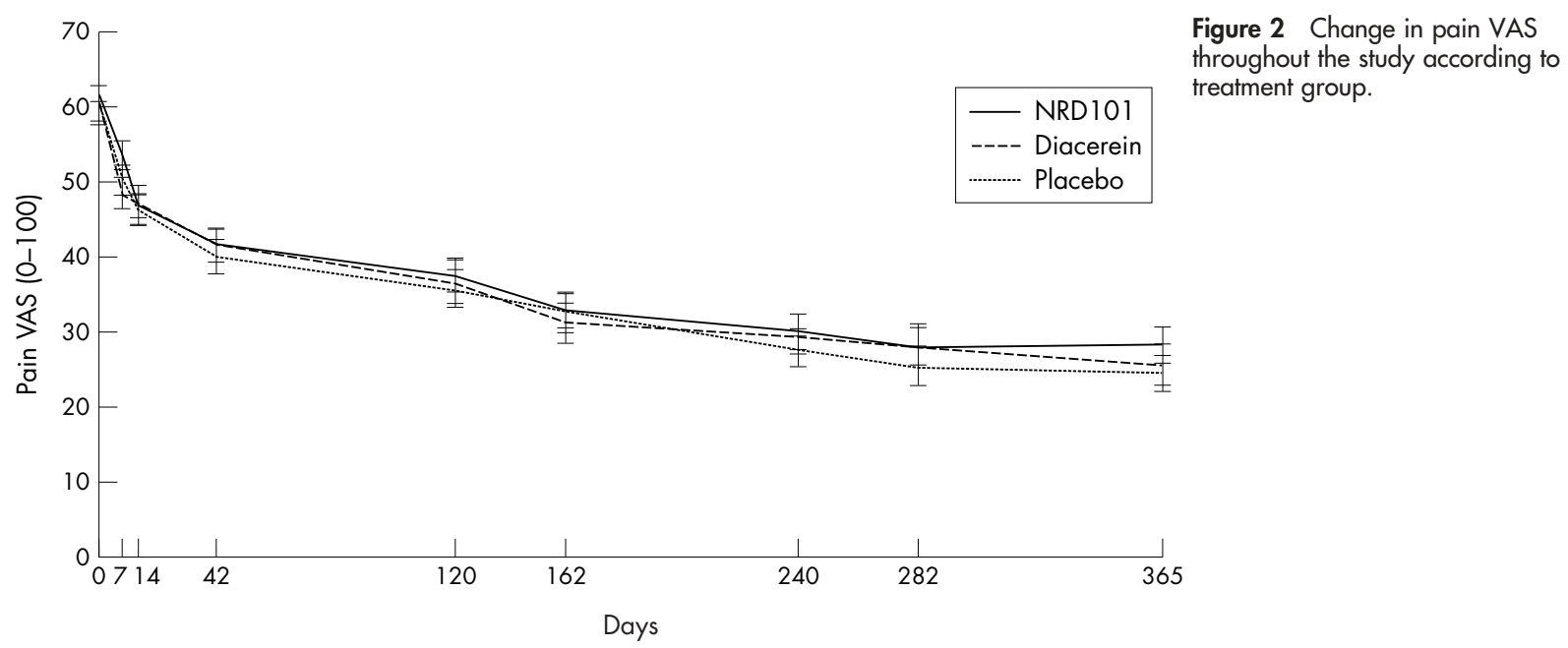

\section{Statistical analysis} Sample size calculation

It was calculated that the inclusion of 280 patients (120 in the HA group and 80 in each of the other groups) would be sufficient to demonstrate a difference, between baseline and 1 year of at least $15 \mathrm{~mm}$ with a standard deviation of $35 \mathrm{~mm}$ on the VAS pain scale between the active and the placebo groups, with an $\alpha$ risk of 0.05 and a power of 0.90 (two tailed test). Moreover, this sample size would also be sufficient to detect a difference of at least $0.40 \mathrm{~mm}$ with a standard deviation of $1 \mathrm{~mm}$ in JSW change from baseline to final visit between the groups $(\alpha=0.05, \beta=0.20$, two tailed test).

\section{Symptomatic outcome measures}

Analysis was made using an intention to treat approach, with the last observation carried forward. The main criterion for assessment of symptomatic efficacy was the pain VAS change between baseline and final visit. Symptomatic efficacy on pain was also evaluated with the following: area under the curve from baseline to final visit, percentage of patients with an improvement of at least $30 \%$ between baseline and final visit (percentage of responders), and change observed for each course of HA injections. The $30 \%$ cut off point was set arbitrarily before the study started. These analyses (change between baseline and final visit, area under the curve, percentage of responders, change by IA injection sequences) were also performed with Lequesne's algofunctional index and the patient's global assessment of disease activity, and the percentage of painful days during the previous month (variance analysis). The number of days on which analgesics or NSAIDs had been used was also assessed.

\section{Structural outcome measures}

Analysis was made using the data of the completer patients. The primary criterion for assessment of structural efficacy was the joint space narrowing (JSN) between baseline and the final visit. The second criterion was the percentage of patients with structural progression. This progression was defined by a JSN $>0.50 \mathrm{~mm}$ during the study, as previously reported. ${ }^{3525}$ Both analyses were made using a $\chi^{2}$ test.

\section{RESULTS}

\section{Patients}

Of 406 screened patients, 301 were considered eligible for the study and were randomised (fig 1). The most common reason for non-inclusion was either a lack of radiographic evidence of knee OA or severe disease with a JSW $<2 \mathrm{~mm}$ at the narrowest point. Of the 301 randomised patients, 19 did not complete the study, with roughly equal numbers of discontinuations, similar times to discontinuation, and similar reasons for withdrawal in each treatment arm (fig 1). At the end of the study, 9/124 (7\%) patients in the NRD101 group, and $5 / 85(6 \%)$ patients in both the diacerein group and the placebo group had discontinued the treatment.

The baseline knee radiograph was obtained in 292 patients and both radiographs (baseline and final) were obtained in 277 patients.

Table 1 summarises the main baseline characteristics of the 301 patients. The demographic, symptomatic and structural characteristics did not differ between the three groups.

\section{Symptomatic efficacy criteria}

Symptomatic outcome measures showed a significant improvement from baseline in the in the three treatment

\begin{tabular}{|c|c|c|c|c|}
\hline $\begin{array}{l}\text { Changes between baseline and final visit } \\
(n=301)\end{array}$ & $\begin{array}{l}\text { NRD101 } \\
(n=131)\end{array}$ & $\begin{array}{l}\text { Diacerein } \\
(\mathrm{n}=85)\end{array}$ & $\begin{array}{l}\text { Placebo } \\
\text { (n=85) }\end{array}$ & $\begin{array}{l}\text { Analysis of } \\
\text { variance } \\
\text { (p value) }\end{array}$ \\
\hline $\begin{array}{l}\text { Pain (0-100 VAS) } \\
\text { Lequesne's algofunctional index* } \\
\text { Patient's global assessment (0-100 VAS) } \\
\text { Percentage of painful days (0-100 VAS) }\end{array}$ & $\begin{array}{l}-33.5(28.5) \\
-20.0(16.5) \\
-29.7(26.9) \\
-43.5(40.3)\end{array}$ & $\begin{array}{l}-33.9(25.7) \\
-18.8(14.7) \\
-32.8(24.0) \\
-45.6(37.8)\end{array}$ & $\begin{array}{l}-34.5(27.4) \\
-18.9(16.9) \\
-31.1(31.7) \\
46.6(37.2)\end{array}$ & $\begin{array}{l}0.96 \\
0.84 \\
0.82 \\
0.83\end{array}$ \\
\hline
\end{tabular}


Table 3 Assessment of the treatment efficacy by the patient and investigator after 1 year's treatment, by treatment group

\begin{tabular}{|c|c|c|c|c|c|c|c|c|}
\hline & \multicolumn{4}{|c|}{ Assessment of treatment efficacy by the patient } & \multicolumn{4}{|c|}{ Assessment of treatment efficacy by the investigator } \\
\hline & NRD101 & Diacerein & Placebo & Total & NRD101 & Diacerein & Placebo & Total \\
\hline \multicolumn{9}{|c|}{ Very good } \\
\hline No & 41 & 18 & 21 & 80 & 41 & 19 & 27 & 87 \\
\hline$\%$ & 34 & 24 & 28 & 29.6 & 33 & 25 & 35 & 31.6 \\
\hline \multicolumn{9}{|l|}{ Good } \\
\hline No & 45 & 31 & 36 & 112 & 45 & 34 & 30 & 109 \\
\hline$\%$ & 38 & 41 & 48 & 41.5 & 37 & 45 & 38 & 39.6 \\
\hline \multicolumn{9}{|l|}{ Moderate } \\
\hline No & 20 & 20 & 15 & 55 & 20 & 15 & 15 & 50 \\
\hline$\%$ & 17 & 27 & 20 & 20.4 & 16 & 20 & 19 & 18.2 \\
\hline \multicolumn{9}{|l|}{ Bad } \\
\hline No & 11 & 3 & 2 & 16 & 14 & 5 & 4 & 23 \\
\hline$\%$ & 9 & 4 & 3 & 5.9 & 11 & 7 & 5 & 8.4 \\
\hline \multicolumn{9}{|l|}{ Very bad } \\
\hline No & 3 & 3 & 1 & 7 & 2 & 2 & 2 & 6 \\
\hline$\%$ & 3 & 4 & 1 & 2.6 & 2 & 3 & 3 & 2.2 \\
\hline \multirow[t]{2}{*}{ Total No } & 120 & 75 & 75 & 270 & 122 & 75 & 78 & 275 \\
\hline & \multicolumn{4}{|c|}{$p=0.28$ (Fisher's exact test) } & \multicolumn{4}{|c|}{$p=0.79$ (Fisher's exact test) } \\
\hline
\end{tabular}

groups. Between baseline and final visit, the mean (SD) change for pain VAS was -33.9 (27.3) $\mathrm{mm}$ (fig 2), for Lequesne's index (0-100 modified scale) -19.3 (16.1), for the patient's global VAS $-31.0(27.6) \mathrm{mm}$, and for the percentage of painful days -45.0 (38.7). However, no statistically significant difference was observed in the intention to treat or completer populations between the different groups (table 2). Similarly, no difference was seen in the consumption of analgesics and NSAIDs. The results were similar when each IA course was analysed separately (data not shown).

No significant difference was seen in the assessment of the treatment efficacy by the patient and by the investigator between the three treatment groups $(p=0.28, p=0.79$, respectively) (table 3 ).

\section{Structural efficacy criteria}

A significant deterioration in the JSW (mean (SD) -0.09 (0.55) $\mathrm{mm}, \mathrm{n}=277, \mathrm{p}=0.01$ ) was seen during the study, but without any significant difference between the three groups $(\mathrm{p}=0.82)$. The percentage of patients with a progression $>0.5 \mathrm{~mm}$ was $17.7 \%, 18.9 \%$, and $20.3 \%(p=0.90)$ in the NRD101, diacerein, and placebo groups, respectively. No difference was seen in the Kellgren and Lawrence score and the osteophyte score between the groups.

\section{Safety}

The number of patients experiencing any adverse event was similar between the three treatment groups: $81.7 \%, 84.7 \%$, and $81.2 \%$ in the NRD101, diacerein, and placebo groups, respectively $(p=0.76)$. Most of these events were mild to moderate in intensity. Table 4 summarises the most commonly seen adverse events. Patients in the NRD101 group had significantly more knee pain during or after IA injection $(p=0.0088)$, and patients treated with diacerein had more diarrhoea $(\mathrm{p}<0.0001)$ and urine colouration $(p=0.0009)$ than patients of the other two groups. Eight patients withdrew from the study owing to adverse events: four, two, and two in the NRDI01, diacerein, and placebo groups, respectively.

\section{DISCUSSION}

This I year, multicentre, randomised, placebo controlled study failed to demonstrate any statistically significant symptomatic or structural effect of NRD101, a new IA hyaluronic acid, compared with placebo or diacerein, an anti-osteoarthritic drug.

Several hypotheses can be suggested to explain the lack of efficacy of a potentially active treatment in such a clinical trial: the study design, a huge placebo response hiding a real treatment effect, and/or a lack of efficacy of the drug.

\begin{tabular}{|c|c|c|c|c|}
\hline Adverse event & $\begin{array}{l}\text { NDR } 101 \\
(n=131)\end{array}$ & $\begin{array}{l}\text { Diacerein } \\
(\mathrm{n}=85)\end{array}$ & $\begin{array}{l}\text { Placebo } \\
(n=85)\end{array}$ & $p$ Value \\
\hline Knee pain during or after IA injection & 24 & 9 & 19 & 0.0088 \\
\hline Diarrhoea & 9 & 41 & 8 & $<0.0001$ \\
\hline Nausea, vomiting & 4 & 5 & 5 & 0.73 \\
\hline Gastralgia & 4 & 8 & 5 & 0.43 \\
\hline Other gastrointestinal disorders & 9 & 18 & 7 & 0.07 \\
\hline Respiratory system disorders (bronchitis, rhinitis...) & 17 & 12 & 16 & 0.48 \\
\hline Influenza-like symptoms & 3 & 5 & 5 & 0.80 \\
\hline Skin disorders & 9 & 8 & 1 & 0.06 \\
\hline $\begin{array}{l}\text { Central and peripheral nervous disorders (headache, } \\
\text { vertigo..) }\end{array}$ & 8 & 5 & 2 & 0.16 \\
\hline Urine colouration & 0 & 7 & 0 & 0.0009 \\
\hline
\end{tabular}


Firstly, concerning the study design itself-this trial was designed and conducted with good practice conditions. ${ }^{25}{ }^{26} \mathrm{It}$ was a three arm, randomised, double blind, placebo controlled trial, approved by an ethical committee. The pain and function outcome variables were similar to those used in other HA and diacerein studies ${ }^{27-29}$ which demonstrated a positive effect on pain and/or on function. The sample size was calculated before the study, and the number of patients in each arm was greater than most of the previous positive HA trials.

The $x$ ray examination methodology was particularly careful, with: (a) verification of the entire set of baseline radiographs by the same observer (PhR), before inclusion, to ensure their quality. If the quality was unsatisfactory, the patient was not included in the study; $(b)$ the $x$ ray technique was carefully described in a booklet handed to each radiography centre. The technique aimed at obtaining films with a constant and reproducible position for each patient and for the $x$ ray beam; (c) the two observers who analysed the films were unaware of the treatment group, the sequence of radiographs, and of the results of the other observer. Their inter- and intraobserver reproducibilities were evaluated before the clinical trial, and the coefficients of correlation were high.

Despite this careful $x$ ray methodology, the study design has some limitations: $(a)$ the extended $x$ ray view choice may not be optimal for detecting narrowing compared with a semiflexed view, but at the time of the study start, the semiflexed view was not yet the preferred method; $(b)$ the femoropatellar compartment was not taken into account in the study; $(c)$ the study duration based on previous personal data might have been too short to demonstrate any structural change in the knee.

Secondly, a huge placebo response due to IA injection might operate quite independently of the injections, and be sufficient to skew the results of the three groups, swamping any difference between them. This hypothesis has already been proposed by Henderson et al, ${ }^{30}$ who also published a negative randomised placebo controlled HA trial. It is well known that injectable treatments have a higher placebo effect than oral treatments. In the database used to elaborate the OARSI responder criteria, the placebo effect was dramatically more important for the patients treated with IA injections than for those treated with oral placebo. ${ }^{31}{ }^{32}$ In the OARSI database the mean (SD) observed change in the 0-100 pain outcome variable between baseline and the final visit in the placebo group was $-24(40) \mathrm{mm}$ for IA HA trials $(n=99)$ versus $-4(73) \mathrm{mm}$ for the oral NSAID trials $(n=175)$. The observed placebo effect seen in our trial was clearly higher $(-34.5(27.4) \mathrm{mm}$ for pain), although it appeared that, in comparison with previous studies, the patients treated with NRDI01 in the present study obtained approximately the same pain relief as those in previous studies. ${ }^{18}{ }^{33-36}$ This might explain our inability to demonstrate any difference between groups, particularly between the placebo group and the diacerein group.

Three randomised controlled trials have evaluated the efficacy and safety of diacerein in patients with hip or knee $\mathrm{OA},{ }^{3}{ }^{10}{ }^{11}$ with two of those trials showing that diacerein has significant symptomatic effectiveness on pain compared with placebo $(\mathrm{n}=772) .{ }^{10}{ }^{11}$ However, in the more recent trial, no statistically significant difference in the symptomatic variables between the diacerein group and the placebo group was found $(\mathrm{n}=507)$. $^{3}$

Lastly, the lack of demonstration of a symptomatic treatment effect might be explained by a real lack of efficacy of the tested new HA, NRDl0l. The pain relieving mechanism of IA injections of HA is unknown. Multiple mechanisms of action have been proposed to explain the therapeutic efficacy of the hyaluronan agents, including effects on physical and biomechanical properties of the joint, effects on cartilage biosynthesis and degradation, anti-inflammatory effects, and a direct analgesic effect related to interaction with pain receptors. ${ }^{37-40}$ Several studies with various preparations of HA from different sources and of differing molecular weights have been conducted. ${ }^{14}{ }^{36}{ }^{41-43}$ Although the variances in molecular weight and other methodological variations in trial design make direct comparisons difficult, there is some evidence of long term pain reduction with IA HA versus placebo for up to 6 months after treatment (effect size $v$ placebo varying from 0.0 to 0.90$){ }^{44}$

One of the mechanisms of action discussed concerns the molecular weight of the HA compound used. The average molecular weight of NRD101 is $1.900 \mathrm{kDa}$. A first trial compared the efficacy of two different HA compounds with different molecular weights and it failed to demonstrate any difference in clinical efficacy between the two preparations evaluated (1.000 kDa $v 7.000 \mathrm{kDa}){ }^{18}$ Furthermore, these preparations did not differ from placebo injections, as assessed by patient related outcome variables.

Another comparison between two different preparations of hyaluronan suggested a greater pain relieving effect of higher molecular weight HA (6.000 kDa) than of a lower molecular weight HA $(0.75 \mathrm{kDa}) .{ }^{45}$ This study lacked a saline injection control group. Moreover, further analysis of the complete database of this trial (original four arm study) failed to demonstrate any benefit of the higher molecular weight HA over the two other comparator HA compounds $(0.800$ and $2.000 \mathrm{kDa}$ ) or the denatured control Synvisc preparation. ${ }^{46}$

Our study failed also to demonstrate any structural efficacy of NRD101 and diacerein compared with placebo. The potential for structural modification by HA (Hyalgan) was first evaluated in a pilot prospective, controlled study of 1 year's duration of 36 patients with OA. ${ }^{4}$ After randomisation, either conventional treatment or three courses of three IA injections of Hyalgan were given at 3 month intervals, as in our study. Arthroscopic assessment showed decreased deterioration in structural variables in the Hyalgan treated group, suggesting that repeated IA injections might delay disease progression. However, this study failed to demonstrate any structural effects using JSW as outcome measure, although it did show a structural effect using two different arthroscopic grading systems.

A recent 1 year multicentre randomised placebo controlled, double blind trial evaluated structure modification in knee OA using IA injections of $0.500-0.730 \mathrm{kDa}$ HA (Hyalgan). The change in the JSW between baseline and final visit was compared by analysis of variance. The mean (SD) loss in the HA group was $-0.22(1.1)$ and in the placebo group 0.60 (1.1) $(\mathrm{p}<0.05)$, suggesting that the HA used had structural efficacy.$^{47}$ Using the same structural outcome variables and a careful radiographic methodology, we failed to show similar results.

Although treatment with diacerein for 3 years has shown a significant structure modifying effect as compared with placebo in the hip, ${ }^{3}$ we did not see any effect of this treatment in the knee after 1 year. In the ECHODIAH trial, radiographic progression of $0.5 \mathrm{~mm}$ was seen in $29.2 \%$ of patients receiving diacerein and $35.7 \%$ receiving placebo at the end of the first year. In comparison, in our study, the percentages of progressors were 18.9 and $20.3 \%$ in the diacerein and placebo groups, respectively. In view of these results, it might be suggested that OA progression may be easier to detect in the hip than in the knee.

In conclusion, this first controlled trial comparing a potential oral structure modifying drug with an IA antiosteoarthritic drug in knee OA failed to demonstrate any benefit of these potentially symptomatic and structure 
modifying drugs compared with placebo. The place of these treatments in the management of knee OA is still debated, ${ }^{48} 49$ and further studies are needed.

\section{Authors' affiliations \\ T Pham, Conception Hospital, AP-HM, Service de Rhumatologie Sud, Marseille, France}

A Le Henanff, Ph Ravaud, Groupe Hospitalier Bichat-Claude Bernard, AP-HP, Xavier Bichat University, Paris, France

P Dieppe, Health Services Research Collaboration, University of Bristol, Bristol, UK

L Paolozzi, M Dougados, Cochin Hospital, AP-HP, René Descartes University, Paris, France

\section{REFERENCES}

1 Lawrence RC, Helmick CG, Arnett FC, Deyo RA, Felson DT, Giannini EH, et al. Estimates of the prevalence of arthritis and selected musculoskeletal disorders in the United States. Arthritis Rheum 1998;41:778-99.

2 Creamer P, Hochberg MC. Osteoarthritis. Lancet 1997;350:503-8.

3 Dougados M, Nguyen M, Berdah L, Mazieres B, Vignon E, Lequesne M. Evaluation of the structure-modifying effects of diacerein in hip osteoarthritis: ECHODIAH, a three-year, placebo-controlled trial. Evaluation of the Chondromodulating Effect of Diacerein in OA of the Hip. Arthritis Rheum 2001:44:2539-47.

4 Listrat V, Ayral X, Patarnello F, Bonvarlet JP, Simonnet J, Amor B et al. Arthroscopic evaluation of potential structure modifying activity of hyaluronan (Hyalgan) in osteoarthritis of the knee. Osteoarthritis Cartilage 1997;5:153-60.

5 Reginster JY, Deroisy R, Rovati LC, Lee RL, Lejeune E, Bruyere O, et al. Long term effects of glucosamine sulphate on osteoarthritis progression: a randomised, placebo-controlled clinical trial. Lancet 2001;357:251-6.

6 Martel-Pelletier J, Mineau F, Jolicoeur FC, Cloutier JM, Pelletier JP. In vitro effects of diacerhein and rhein on interleukin 1 and tumor necrosis factoralpha systems in human osteoarthritic synovium and chondrocytes. J Rheumatol 1998;25:753-62.

7 Moore AR, Greenslade KJ, Alam CA, Willoughby DA. Effects of diacerhein on granuloma induced cartilage breakdown in the mouse. Osteoarthritis Cartilage 1998;6:19-23.

8 Boittin M, Redini F, Loyau G, Pujol JP. [Effect of diacerhein (ART 50) on the matrix synthesis and collagenase secretion by cultured joint chondrocytes in rabbits]. Rev Rhum Ed Fr 1993;60:68-76S.

9 Pelletier JP, Mineau F, Fernandes JC, Duval N, Martel-Pelletier J. Diacerhein and rhein reduce the interleukin 1 beta stimulated inducible nitric oxide synthesis level and activity while stimulating cyclooxygenase-2 2 synthesis in human osteoarthritic chondrocytes. J Rheumatol 1998;25:2417-24.

10 Pelletier JP, Yaron M, Haraoui B, Cohen P, Nahir MA, Choquette D, et al. Efficacy and safety of diacerein in osteoarthritis of the knee: a double-blind, placebo-controlled trial. The Diacerein Study Group. Arthritis Rheum 2000:43:2339-48.

11 Nguyen M, Dougados M, Berdah L, Amor B. Diacerhein in the treatment of osteoarthritis of the hip. Arthritis Rheum 1994;37:529-36.

12 Ayral X. Injections in the treatment of osteoarthritis. Best Pract Res Clin Rheumatol 2001;15:609-26.

13 Peyron JG. A new approach to the treatment of osteoarthritis: viscosupplementation. Osteoarthritis Cartilage 1993;1:85-7.

14 Kirwan JR, Rankin E. Intra-articular therapy in osteoarthritis. Baillieres Clin Rheumatol 1997; 11:769-94.

15 Schiavinato A, Lini E, Guidolin D, Pezzoli G, Botti P, Martelli M, et al. Intraarticular sodium hyaluronate injections in the Pond-Nuki experimental model of osteoarthritis in dogs. II. Morphological findings. Clin Orthop 1989:286-99.

16 George E. Intra-articular hyaluronan treatment for osteoarthritis. Ann Rheum Dis 1998;57:637-40

17 Brandt KD, Smith GN Jr, Simon LS. Intraarticular injection of hyaluronan as treatment for knee osteoarthritis: what is the evidence? Arthritis Rheum 2000;43:1 192-203

18 Karlsson J, Sjogren LS, Lohmander LS. Comparison of two hyaluronan drugs and placebo in patients with knee osteoarthritis. A controlled, randomized, double-blind, parallel-design multicentre study. Rheumatology (Oxford) 2002;41:1240-8.

19 Yamamoto M, Sugarawa S, Tsukamoto Y, Motegi M, Iwata H, Ryu J, et al. Clinical evaluation of high molecular weight sodium hyaluronate (NRD 101) on osteoarthritis of the knee. A phase III comparative clinical study with Artz as a control drug. Jpn Pharmacol Ther 1994;22:4059-87.

20 Tsukamoto Y, Yamamoto M, Motegi M, Iwata H, Ryu J, Takagishi K, et al. A double-blind trial of intra-articular higher molecular weight hyaluronic acid (NRD101) versus lower molecular weight hyaluronic acid (Artz) in knee osteoarthritis. Rheum Eur 1995;24:333.

21 Ravaud P, Auleley GR, Chastang C, Rousselin B, Paolozzi L, Amor B, et al. Knee joint space width measurement: an experimental study of the influence of radiographic procedure and joint positioning. $\mathrm{Br} J$ Rheumatol 1996;35:761-6.
22 Ravaud P, Giraudeau B, Auleley GR, Drape JL, Rousselin B, Paolozzi L, et al. Variability in knee radiographing: implication for definition of radiological progression in medial knee osteoarthritis. Ann Rheum Dis 1998;57:624-9.

23 Kellgren JH, Lawrence JS. Radiological assessment of osteoarthritis. Ann Rheum Dis 1957;16:494-502.

24 Altman RD, Hochberg M, Murphy WA Jr, Wolfe F, Lequesne M. Atlas of individual radiographic features in osteoarthritis. Osteoarthritis Cartilage 1995;3(suppl A):3-70

25 Lequesne M, Brandt K, Bellamy N, Moskowitz R, Menkes CJ, Pelletier JP, et al. Guidelines for testing slow acting drugs in osteoarthritis. J'Rheumatol Suppl 1994;41:65-71; discussion 72-3; erratum, 2395.

26 Altman R, Brandt K, Hochberg M, Moskowitz R, Bellamy N, Bloch DA, et al. Design and conduct of clinical trials in patients with osteoarthritis: recommendations from a task force of the Osteoarthritis Research Society. Results from a workshop. Osteoarthritis Cartilage 1996;4:217-43.

27 Altman RD, Moskowitz R. A randomized clinical trial of intra-articular sodium hyaluronate in patients with osteoarthritis of the knee: a summary. Am J Orthop $1999 ; 28: 3-4$

28 Brandt KD, Block JA, Michalski JP, Moreland LW, Caldwell JR, Lavin PT. Efficacy and safety of intraarticular sodium hyaluronate in knee osteoarthritis. ORTHOVISC Study Group. Clin Orthop 2001:130-43.

29 Jones AC, Pattrick M, Doherty S, Doherty M. Intra-articular hyaluronic acid compared to intra-articular triamcinolone hexacetonide in inflammatory knee osteoarthritis. Osteoarthritis Cartilage 1995;3:269-73.

30 Henderson EB, Smith EC, Pegley F, Blake DR. Intra-articular injections of 750 $\mathrm{kD}$ hyaluronan in the treatment of osteoarthritis: a randomised single centre double-blind placebo-controlled trial of 91 patients demonstrating lack of efficacy. Ann Rheum Dis 1994;53:529-34.

31 Dougados M, Leclaire P, van der Heijde D, Bloch DA, Bellamy N, Altman RD. Response criteria for clinical trials on osteoarthritis of the knee and hip: a report of the Osteoarthritis Research Society International Standing Committee for Clinical Trials response criteria initiative. Osteoarthritis Cartilage 2000;8:395-403.

32 Villani P, Bouvenot G. [Assessment of the placebo effect of symptomatic slowacting anti-arthritics]. Presse Med 1998;27:211-14.

33 Puhl W, Scharf P. Intra-articular hyaluronan treatment for osteoarthritis. Ann Rheum Dis 1997;56:441.

34 Lohmander LS, Dalen N, Englund G, Hamalainen M, Jensen EM, Karlsson K, et al. Intra-articular hyaluronan injections in the treatment of osteoarthritis of the knee: a randomised, double blind, placebo controlled multicentre trial. Hyaluronan Multicentre Trial Group. Ann Rheum Dis 1996;55:424-31.

35 Dahlberg L, Lohmander LS, Ryd L. Intraarticular injections of hyaluronan in patients with cartilage abnormalities and knee pain. A one-year double-blind, placebo-controlled study. Arthritis Rheum 1994;37:521-8.

36 Dougados $M$, Nguyen $M$, Listrat $V$, Amor B. High molecular weight sodium hyaluronate (hyalectin) in osteoarthritis of the knee: a 1 year placebocontrolled trial. Osteoarthritis Cartilage 1993;1:97-103.

37 Moskowitz RW. Hyaluronic acid supplementation. Curr Rheumatol Rep 2000;2:466-71.

38 Ghosh P, Read R, Numata Y, Smith S, Armstrong S, Wilson D. The effects of intraarticular administration of hyaluronan in a model of early osteoarthritis in sheep. II. Cartilage composition and proteoglycan metabolism. Semin Arthritis Rheum 1993;22:31-42.

39 Laurent TC, Fraser JR. Hyaluronan. FASEB J 1992;6:2397-404.

40 Laurent TC, Laurent UB, Fraser JR. Functions of hyaluronan. Ann Rheum Dis 1995:54:429-32.

41 Grecomoro G, Martorana U, Di Marco C. Intra-articular treatment with sodium hyaluronate in gonarthrosis: a controlled clinical trial versus placebo. Pharmatherapeutica 1987:5:137-41.

42 Dixon AS, Jacoby RK, Berry H, Hamilton EB. Clinical trial of intra-articular injection of sodium hyaluronate in patients with osteoarthritis of the knee. Curr Med Res Opin 1988;11:205-13.

43 Towheed TE, Hochberg MC. A systematic review of randomized controlled trials of pharmacological therapy in osteoarthritis of the knee, with an emphasis on trial methodology. Semin Arthritis Rheum 1997;26:755-70.

44 Pham T, Fransen M, Ravaud P, Dougados M. Osteoarthritis. In: Evidence based rheumatology. London: BMJ, (in press).

45 Wobig M, Dickhut A, Maier R, Vetter G. Viscosupplementation with hylan G-F 20: a 26-week controlled trial of efficacy and safety in the osteoarthritic knee. Clin Ther 1998;20:410-23.

46 Allard $S$, O'Regan $M$. The role of elastoviscosity in the efficacy of viscosupplementation for osteoarthritis of the knee: a comparison of hylan G-F 20 and a lower-molecular-weight hyaluronan. Clin Ther 2000;22:792-5.

47 Jubb RW, Piva S, Beinat L, Dacre J, Gishen P. A one-year, randomised, placebo (saline) controlled clinical trial of $500-730 \mathrm{kDa}$ sodium hyaluronate (Hyalgan) on the radiological change in osteoarthritis of the knee. Int J Clin Pract 2003;57:467-74.

48 ACR. Recommendations for the medical management of osteoarthritis of the hip and knee: 2000 update. American College of Rheumatology Subcommittee on Osteoarthritis Guidelines. Arthritis Rheum 2000:43:1905-15.

49 Jordan K, Arden N, Doherty M, Bannwarth B, Biilsma JW, Dieppe P, et al. EULAR recommendations 2003: an evidence based medicine approach to the management of knee osteoarthritis. Report of a Task Force of the Standing Committee for International Clinical Studies Including Therapeutic Trials (ESCISIT). Ann Rheum Dis 2003;62:1145-55. 